\begin{tabular}{|c|c|c|}
\hline BIODIK & $\begin{array}{c}\text { BIODIK: Jurnal IImiah Pendidikan Biologi } \\
\text { ISSN 2580-0922 (online), ISSN 2460-2612 (print) } \\
\text { Volume 07, Nomor 04, Tahun 2021, Hal.127-135 } \\
\text { Available online at: } \\
\text { https://online-journal.unja.ac.id/biodik }\end{array}$ & BIODIK \\
\hline
\end{tabular}

Research Article

OPEN ACCESS

\title{
Efektivitas Video Learning Materi Pencemaran Lingkungan Pada Mata Kuliah IImu Lingkungan Prodi Pendidikan Biologi FKIP UAD
}

\section{(The Effectiveness of Video Learning of Environmental Pollution Materials in the Environmental Science Course of Biology Education Study Program, FKIP UAD)}

\author{
Yahya Hanafi¹, Destri Ratna Ma'rifah², Arief Abdillah Nurusman³, Galuh Alif Fahmi Rizki4 \\ 1,2,3 Pendidikan Biologi, FKIP Universitas Ahmad Dahlan \\ 4 Desa Wisata Tinalah Kulonprogo \\ Jl. Kapas No.9, Semaki, Kec. Umbulharjo, Kota Yogyakarta, Daerah Istimewa Yogyakarta 55166 \\ ${ }^{*}$ Corresponding Author: yahya.hanafi@pbio.uad.ac.id
}

\begin{tabular}{|c|c|}
\hline Informasi Artikel & ABSTRACT \\
\hline $\begin{array}{l}\text { Submit: } 21-07-2021 \\
\text { Diterima: } 02-12-2021 \\
\text { Dipublikasikan: } 28-12-2021\end{array}$ & $\begin{array}{l}\text { Biology Education Study Program students, FKIP UAD have a learning style that } \\
\text { tends to be auditive-visual. Based on these student characteristics, it is } \\
\text { necessary to select appropriate and appropriate learning media to retain the } \\
\text { information provided as much as possible. Therefore it is required to use learning } \\
\text { media to accommodate student learning styles, namely by using video learning } \\
\text { media. This study aims to determine the effectiveness of using video learning } \\
\text { material on environmental pollution in the Environmental Science course. Video } \\
\text { learning of environmental pollution material used includes water, soil, and air } \\
\text { pollution. The research design is one-group pretest-postest design. The } \\
\text { research was conduct at the Biology Education Study Program FKIP UAD in } \\
\text { March-August 2018. The population in this study were all students of the Biology } \\
\text { Education Study Program FKIP UAD semester VI academic year 2017-2018, } \\
125 \text { people (class A, B, C). Data collection techniques using observation and } \\
\text { tests. The instruments used were the observation sheet and pre-post test. Data } \\
\text { analysis includes prerequisite tests and hypothesis testing using the gain score } \\
\text { and t-test. The results of the gain score for classes A, B, and C were obtained in } \\
\text { the moderate category (0.3 } \leq g \geq 0.7), \text { meaning that there was an increase in } \\
\text { learning outcomes using video learning. The } t \text {-test shows a significant difference } \\
\text { between the pretest and post-test. The video learning of environmental pollution } \\
\text { material is effectively used in the learning process of Environmental Science. }\end{array}$ \\
\hline & Key words: effectiveness, video learning, environmental pollution \\
\hline Penerbit & ABSTRAK \\
\hline $\begin{array}{l}\text { Program Studi Pendidikan Biologi } \\
\text { FKIP Universitas Jambi, } \\
\text { Jambi- Indonesia }\end{array}$ & $\begin{array}{l}\text { Mahasiswa Prodi Pendidikan Biologi FKIP UAD memiliki gaya belajar yang } \\
\text { cenderung auditif-visual. Berdasarkan karakteristik mahasiswa tersebut } \\
\text { diperlukan pemilihan media pembelajaran yang tepat dan sesuai. Oleh karena } \\
\text { itu perlu menggunakan media pembelajaran yang dapat mengakomodir gaya } \\
\text { belajar mahasiswa, yaitu dengan penggunaan media pembelajaran video. } \\
\text { Penelitian ini bertujuan untuk mengetahui efektivitas penggunaan video learning } \\
\text { materi pencemaran lingkungan pada mata kuliah IImu Lingkungan. Video } \\
\text { learning materi pencemaran lingkungan yang digunakan meliputi materi } \\
\text { pencemaran air, tanah, dan udara. Desain penelitian yaitu one-group pretest- } \\
\text { postest design. Penelitian dilaksanakan di Program Studi Pendidikan Biologi } \\
\text { FKIP UAD pada bulan Maret-Agustus 2018. Sampel penelitian ini mahasiswa } \\
\text { semester VI prodi Pendidikan Biologi FKIP UAD tahun akademik 2017-2018, } \\
\text { berjumlah } 125 \text { orang (kelas A,B,C). Teknik pengumpulan data menggunakan } \\
\text { teknik observasi, dan tes. Instrumen yang digunakan yaitu lembar observasi dan }\end{array}$ \\
\hline
\end{tabular}


soal. Teknik analisis data deskriptif kuantitatif, analisis data meliputi uji prasyarat dan uji hipotesis menggunakan gain score dan uji t. Hasil gain score untuk kelas A, B, dan $\mathrm{C}$ diperoleh kategori sedang $(0,3 \leq \mathrm{g} \geq 0,7)$, artinya terdapat peningkatan hasil belajar dengan menggunakan video learning. Hasil uji $t$ menunjukkan terdapat perbedaan signifikan antara pretes dan postes sehingga video learning materi pencemaran lingkungan efektif digunakan dalam proses pembelajaran IImu Lingkungan.

Kata kunci: efektivitas, video learning, pencemaran lingkungan

\section{(i) (2) (2)}

BY Ne SA

This BIODIK : Jurnal IImiah Pendidikan Biologi is licensed under a CC BY-NC-SA (Creative Commons Attribution-ShareAlike 4.0 International License)

\section{PENDAHULUAN}

Penggunaan video learning materi pencemaran lingkungan dalam proses pembelajaran mata kuliah IImu Lingkungan disesuaikan dengan profil gaya belajar mahasiswa di Program Studi Pendidikan Biologi FKIP UAD. Menurut penelitian Ma'rifah et al. (2019) mahasiswa Prodi Pendidikan Biologi FKIP UAD angkatan 2015 yang menempuh mata kuliah Ilmu Lingkungan memiliki gaya belajar auditif-visual $(61 \%)$, kemudian berikutnya mahasiswa dengan gaya belajar visual $(12,4 \%)$, visual-kinestetik $(11,5 \%)$ dan auditif kinestetik (8,8\%). Pemahaman gaya belajar mahasiswa sangat penting dimiliki oleh pengajar, agar dapat menentukan strategi dan model pembelajaran yang sesuai dengan gaya belajar mahasiswa. Gaya belajar yang dimiliki mahasiswa perlu diupayakan untuk dapat diakomodir agar hasil belajar tercapai secara optimal. Pengajar memiliki peranan untuk mengakomodir gaya belajar mahasiswa dan membantu pengembangan potensi mahasiswa melalui gaya belajar yang dimiliki. Berdasarkan penelitian tersebut agar pembelajaran pada mata kuliah IImu Lingkungan dapat berjalan dengan efektif maka perlu menggunakan media audio-visual yaitu video (Ma'rifah et al., 2019).

Berdasarkan karakteristik mahasiswa tersebut diperlukan pemilihan media pembelajaran yang tepat dan sesuai agar proses pembelajaran dapat berjalan dengan maksimal. Fungsi media pembelajaran yaitu sebagai sarana menyampaikan proses pembelajaran seperti gambar, video, teks dan audio. Media pembelajaran yang mengkombinasikan contoh yang kontekstual dari sumber belajar yang terdapat di lingkungan sekitar akan membantu pemahaman mahasiswa yang masih abstrak (Smaldino et al., 2010). Efektivitas pembelajaran dapat ditingkatkan dengan mengkombinasikan media menjadi multimedia. Multimedia adalah gabungan beberapa media agar dapat menayangkan informasi meliputi kombinasi grafik, video, audio, gambar dan animasi (Ivers \& Barron, 2002).

Video pembelajaran adalah media memiliki kombinasi unsur audio dan visual. Unsur visual untuk memberikan rangsangan indera penglihatan dan unsur audio memberikan rangsangan indera pendengaran. Suatu media yang memiliki unsur auditif dan visual dapat meningkatkan kemampuan mengingat mahasiswa. Video pembelajaran dapat memuat banyak informasi dan dapat digunakan dalam proses pembelajaran sehingga mahasiswa dapat menikmati secara langsung baik audio maupun visualnya (Prastowo, 2014). Salah satu keuntungan video yaitu kemampuan mendokumentasikan peristiwa secara faktual sehingga dapat tersaji fakta-fakta yang otentik, kemudian dapat digunakan sebagai sarana diskusi pada pertemuan tatap muka di kelas (Uno \& Lamatenggo, 2014). Selain itu, video pembelajaran memiliki keuntungan dapat menyajikan banyak informasi yang lugas, pesan serta materi dapat disampaikan kepada mahasiswa secara langsung (audio visual). Ukuran tampilan video dapat disesuaikan dengan kebutuhan sehingga fleksibel sesuai dengan masing-masing mahasiswa (Daryanto, 
2010). Penggunaan video pembelajaran memberikan manfaat antara lain dapat menunjukkan tahapan secara sistematis, menunjukkan interaksi antara dua orang atau lebih, menyajikan gambaran secara nyata (audio visual), dapat menunjukkan studi kasus dari kehidupan sehari-hari sehingg dapat memicu diskusi dan memberikan pengalaman belajar secara nyata kepada mahasiswa (Prastowo, 2014). Menurut Ningtiyas and Anistyasari (2020) melalui video mahasiswa dapat melihat serta mempelajaran materi berulang-ulang sesuai dengan kebutuhan sehingga dapat memudahkan mahasiswa memahami materi yang diberikan. Video merupakan media pembelajaran yang sesuai digunakan di e-learning, dapat memberikan informasi dengan cara yang menarik serta konsisten (Zhang et al., 2006).

Mata kuliah IImu Lingkungan di program studi Pendidikan Biologi FKIP UAD mempelajari beberapa topik materi yang abstrak dan kompleks, membutuhkan penjelasan secara langsung dengan menggunakan objek di sekitar. Salah satu topik materi yang kompleks dan abstrak yaitu pencemaran lingkungan meliputi air, tanah dan udara. Materi pencemaran lingkungan mempelajari tentang definisi pencemaran, identifikasi sumber pencemar, indikator pencemaran, dampak pencemaran dan konsep pencemaran yang tidak punya batas negara dapat menyebar ke segala penjuru. Berdasarkan karakteristik materi pencemaran lingkungan tersebut maka dibutuhkan media pembelajaran berupa video yang selanjutnya disebut dengan istilah video learning untuk menyajikan fakta-fakta di lingkungan sekitar secara langsung dan memberikan gambaran secara nyata terkait materi pencemaran lingkungan. Video learning yang dikembangkan menyajikan fakta lapangan dan uji coba sederhana pencemaran air, udara, dan tanah. Melalui penggunaan video dalam proses pembelajaran pada mata kuliah IImu Lingkungan diharapkan dapat meningkatkan pemahaman dan hasil belajar mahasiswa. Video learning materi pencemaran lingkungan diharapkan dapat membantu mahasiswa mempelajari materi-materi yang masih abstrak dan kompleks pada mata kuliah IImu Lingkungan. Teori belajar konstruktivisme menekankan pada keterlibatan siswa dalam proses pembelajaran dibandingkan aktivitas siswa mencari jawaban yang benar. Teori konstruktivisme memerlukan lingkungan belajar yang lebih kaya dengan sumber belajar, hal tersebut kontras dengan ciri pembelajaran di lingkungan kelas yang kurang interaktif, mengandalkan instruktur, buku maupun pengajar. Media grafik dan video dapat membuat siswa lebih tertarik dan terlibat dalam pembelajaran. Pembelajaran berbasis web (e-learning) merupakan implementasi teori konstruktivisme, yang memberikan kesempatan peserta didik untuk terlibat dalam interaksi, kreativitas, dam kolaborasi selama mengkonstruksi suatu pengetahuan (Zhang et al., 2006). Oleh karena itu, dikembangkan video pembelajaran pada mata kuliah IImu Lingkungan dengan topik materi pencemaran air, udara, dan tanah. Video materi pencemaran lingkungan yang dikembangkan berjumlah 3 video, masing-masing untuk materi pencemaran udara, air, dan tanah. Video yang dikembangkan disusun berbasis kontekstual yaitu video diambil dari 3 lokasi yaitu Sungai Gajang Wong untuk materi pencemaran air, Tempat Pembuangan Akhir Sampah Piyungan untuk materi pencemaran tanah, dan Ringroad Ketandan Yogyakarta untuk video pencemaran udara. Tiga video materi pencemaran lingkungan yang dikembangkan tersebut memperoleh penilaian sangat baik dari ahli materi dan media, dinyatakan layak digunakan dalam proses pembelajaran (Hanafi \& Ma'rifah, 2018).

Video materi pencemaran lingkungan digunakan dalam proses pembelajaran pada mata kuliah IImu Lingkungan di Prodi Pendidikan Biologi dengan menggunakan menggunakan e-learning UAD dengan model blended learning. E-learning merupakan cara penyamapaian (interaksi) melalui teknologi, atau metode berbasis online. E-learning juga merupakan bagian dari pedagogi (Caterhall, 2005). Penggunaan e-learning juga untuk mengakomodasi gaya belajar mahasiswa selain auditif visual juga cenderung mencari sumber referensi dari internet menggunakan gadget yang dimiliki (Ma'rifah et al., 2019). Menurut Battezzati et al. (2004) e-learning dibagi menjadi 4 model yaitu virtual classroom, tele- 
teaching, blended learning dan collaborative learning. Blended learning merupakan integrasi sumber daya internet ke dalam pengajaran dan pembelajaran dalam rangka memanfaatkan potensi teknologi informasi dan komunikasi tanpa meninggalkan pembelajaran tatap muka tradisional. Menurut Rizki and Daniamiseno (2019) blended learning merupakan model pembelajaran yang mengkombinasikan pembelajaran tatap muka di kelas dengan pembelajaran online secara sistematis. Kombinasi pembelajaran tatap muka dengan pembelajaran online mempertimbangkan karakteristik materi serta karakateristik mahasiswa agar pembelajaran dapat berjalan dengan efektif dan efisien.

Penelitian ini bertujuan untuk mengetahui efektivitas penggunaan video learning materi pencemaran lingkungan pada mata kuliah IImu Lingkungan di Program Studi Pendidikan Biologi FKIP UAD. Penelitian ini diharapkan dapat memberikan informasi apakah video materi pencemaran lingkungan yang dikembangkan efektif digunakan dalam proses pembelajaran pada mata kuliah IImu Lingkungan, sehingga diharapkan dapat diperoleh masukan-masukan untuk video yang dikembangkan.

\section{METODE PENELITIAN}

Jenis penelitian ini yaitu quasi experimental karena penelitian ini belum merupakan eksperimen sebenarnya, masih terdapat variabel lain yang akan mempengaruhi variabel dependen. Penelitian ini menggunakan satu kelompok eksperimen yang akan diberikan perlakuan yaitu mahasiswa semester $\mathrm{VI}$ prodi Pendidikan Biologi FKIP UAD yang akan diajarkan dengan video learning pada materi pencemaran lingkungan. Desain penelitian yang digunakan dalam penelitian ini yaitu one-group pretest-postest design Grup A 01 -------- X --------- 02 (Creswell, 2014). Penelitian dilaksanakan di Program Studi Pendidikan Biologi FKIP UAD. Waktu pelaksanaan penelitian pada bulan Maret - Agustus 2018. Populasi yang digunakan yaitu seluruh mahasiswa Prodi Pendidikan Biologi semester VI peserta mata kuliah IImu Lingkungan tahun akademik 2017-2018. Jumlah mahasiswa yang digunakan sebagai sampel yaitu 125 orang terbagi menjadi 3 kelas $(A, B, C)$. Teknik pengumpulan data menggunakan teknik observasi, tes, dan dokumentasi. Instrumen yang digunakan yaitu lembar observasi dan soal berupa pretes dan postes yang akan diberikan sebelum melihat video learning materi pencemaran lingkungan dan setelah melihat video learning. Pretes dan postes akan diberikan melalui elearning, masing-masing mahasiswa mengerjakan soal secara online dengan akun elearning masing-masing. Teknik analisis data adalah deskriptif kuantitatif, analisis data meliputi uji prasyarat dengan uji normalitas, dan uji hipotesis menggunakan gain score dan uji-t menggunakan SPSS.

\section{HASIL PENELITIAN DAN PEMBAHASAN}

Produk video materi pencemaran lingkungan sudah dikembangkan melalui proses R\&D dan memperoleh kategori penilaian sangat baik, layak digunakan dalam proses pembelajaran IImu Lingkungan (Hanafi \& Ma'rifah, 2018). Video materi pencemaran lingkungan digunakan dalam proses pembelajaran IImu Lingkungan menggunakan e-learning dengan model blended learning. Melalui model blended learning aktivitas pembelajaran tidak sepenuhnya dilakukan secara online, tetapi dikombinasikan antara online dan tatap muka. E-learning digunakan untuk memberikan instruksi aktivitas yang harus dilakukan dalam pembelajaran mata kuliah IImu Lingkungan, baik aktivitas sebelum maupun sesudah pembelajaran tatap muka di kelas. Video materi pencemaran lingkungan yang dikembangkan disajikan menjadi bagian dari instruksi pembelajaran pada sesi materi pencemaran air, udara dan tanah. Materi pencemaran air, udara dan tanah masing-masing memiliki instruksi pembelajarannya tersendiri, mahasiswa akan mengakses instruksi kegiatan pembelajaran maupun sumber belajar lainny melalui elearning masing-masing. Sebelum melakukan pembelajaran tatap muka di kelas setiap mahasiswa harus 
melakukan aktivitas sebelum pertemuan tatap muka yang sudah disajikan di e-learning. Sesi pertemuan tatap muka digunakan untuk kegiatan pengayaan serta pendalaman berdasarkan aktivitas yang sudah dilakukan sebelum mengikuti tata muka di kelas.

Sebelum proses pembelajaran tatap muka materi pencemaran lingkungan dengan menggunakan video learning, mahasiswa diberi soal berupa pretes materi pencemaran air, udara dan tanah. Kemudian setelah mengikuti pembelajaran materi pencemaran lingkungan, mahasiswa diberi soal postes. Hasil uji prasyarat dengan uji homogenitas memberikan hasil nilai signifikan $>0,05(0,338>0,05)$, maka maka Ho diterima (varian sama), sehingga asumsi homogenitas terpenuhi. Selanjutnya hasil uji hipotesis menggunakan gain score disajikan pada Tabel 1.

Tabel 1. Hasil gain score

\begin{tabular}{|c|c|c|c|}
\hline Nilai & Kelas A & Kelas B & Kelas C \\
\hline Rerata nilai prates & 50,00 & 47,01 & 52,06 \\
\hline Rerata nilai postes & 66,47 & 70,18 & 72,70 \\
\hline Nilai tertinggi & 100,00 & 100,00 & 100,00 \\
\hline Gain & 0,33 & 0,44 & 0,43 \\
\hline Kategori & sedang & sedang & sedang \\
\hline
\end{tabular}

Berdasarkan hasil gain score untuk kelas $A, B$, dan $C$ diperoleh kategori sedang $(0,3 \leq g \geq 0,7)$. Artinya terdapat peningkatan hasil belajar dengan menggunakan video materi Pencemaran Lingkungan. Hasil uji hipotesis menggunakan uji t hasil bahwa terdapat perbedaan signifikan antara pretes dan postes, tetapi dengan kenaikan gain sedang. Penggunaan video learning materi pencemaran dapat meningkatkan hasil belajar dapat dikarenakan karena mahasiswa lebih mudah memahami materi yang disampaikan serta mampu mengingat informasi yang lebih banyak. Hal tersebut sesuai dengan pernyataan (Munir, 2013), bahwa orang hanya mampu mengingat 30\% dari yang didengar dan $20 \%$ dari yang dilihat. Apabila mendengar dan melihat langsung orang mampu mengingat sebesar $50 \%$, dan dapat mengingat informasi sampai $80 \%$ jika melihat, mendengar, dan melakukan sekaligus. Video memungkinkan peserta didik melihat objek sebenarnya secara nyata, melihat aktivitas/adegan secara nyata dan dapat mendengarkan narasi dari video (Zhang et al., 2006). Menurut penelitian Hill \& Nelson (2011) siswa percaya melalui video podcast dapat menguatkan serta mengembangkan catatan perkuliahan yang diberikan pengajar. Kekuatan utama video podcast pembelajaran yaitu dapat membantu mengingat fakta-fakta yang diperoleh serta membatu pemahaman secara lebih mendalam. Hal tersebut diperkuat dengan penelitian El-Ariss et al. (2021) performa siswa yang menggunakan video pembelajaran lebih baik dibandingkan kelompok siswa yang tidak menggunakan video dalam pembelajarannya.

Media pembelajaran menggunakan video akan memudahkan mahasiswa untuk memahami dan mengingat materi perkuliahan yang disampaikan karena dapat menggunakan indera penglihatan dan indera pendengaran dalam menerima informasi. Keberadaan media pembelajaran berupa video akan membantu mahasiswa mengingat lebih banyak informasi yang diberikan, karena video memiliki konten unsur audio dan visual. Pemahaman mahasiswa akan dapat ditingkatkan lagi jika konten dalam video terdapat informasi untuk mempraktekkan langsung. Hal tersebut didukung dengan hasil penelitian studi literatur Ningtiyas and Anistyasari (2020), penggunaan video sebagai media pembelajaran di perguruan tinggi cukup efektif digunakan oleh mahasiswa. Media video memberikan kesempatan kepada mahasiswa untuk melihat serta berlatih secara berulang sehingga membuat mahasiswa lebih mudah 
memahami materi. Video sangat efektif digunakan dalam proses pembelajaran, mahasiswa akan lebih mudah mempelajari materi. Mahasiswa dapat melihat video podcast pembelajaran di rumah atau bahkan saat di perjalanan. Ruang pembelajaran di kelas diperluas dengan hadirnya teknologi (video podcast) ke dalam ruang yang informal yang ditentukan oleh penggunanya sendiri yang sifatnya fleksibel baik secara waktu dan ruang. Melalui video podcast peserta didik dapat merasa nyaman ketika akses dari rumah, dapat memungkinkan untuk memutar ulang video untuk mencari informasi, membuat catatan, mengkonfirmasi isu-isu yang diterima serta menguatkan informasi-informasi yang penting. Banyak siswa lebih menyukai melihat video podcast di rumah agar lebih konsentrasi dalam proses pembelajaran (ElAriss et al., 2021; Hill \& Nelson, 2011).

Menurut Nadhianty and Purnomo (2020) video merupakan media yang efektif digunakan untuk pendidikan jarak jauh karena memuat unsur audio dan visual sehingga memiliki kesamaan dengan pembelajaran tatap muka di kelas. Video pembelajaran juga memiliki fleksibilitas tinggi karena dapat diakses kapan saja dan dimana saja. Selain itu video pembelajaran dapat melatih mahasiswa berpikir secara konkret, logis, realistis dan kreatif. Peningkatan hasil belajar juga dapat disebabkan oleh penggunaan media pembelajaran berupa video telah sesuai dengan profil gaya belajar mahasiswa yang cenderung auditif dan visual (Ma'rifah et al., 2019). Menurut Prastowo (2014), video memuat informasi yang banyak, dapat dimanfaatkan dalam proses pembelajaran sehingga mahasiswa dapat melihat secara langsung. Unsur audio untuk merangsang indera pendengaran dan konten visual untuk merangsang penglihatan. Media yang disajikan dengan unsur auditif dan visual akan meningkatkan kemampuan mengingat mahasiswa. Manfaat penggunaan video pembelajaran antara lain: mampu menunjukkan interaksi antara dua orang atau lebih; menunjukan tahapan prosedur; mampu memberikan gambaran secara nyata; memberikan pengalaman belajar kepada mahasiswa; dan mampu menunjukkan studi kasus dalam kehidupan sehari-hari yang dapat memicu diskusi. Video pembelajaran memuat unsur audio dan visual yang dapat berisi konten/pesan pembelajaran dalam bentuk prinsip, teori, konsep, fakta dan prosedur yang dapat memudahkan serta membantu mahasiswa memahami materi (Nadhianty \& Purnomo, 2020). Penelitian Patterson et al. (2020) menunjukkan bahwa siswa lebih banyak akses video pembelajaran pendek (durasi kurang lebih 15 menit) dibandingkan video-video dengan durasi lebih Panjang (lebih dari 1 jam). Video pendek membantu untuk menjaga pengetahuan dan secara konsisten dapat membantu persiapan penilaian serta efektif untuk membatu pemahaman dan retensi konsep.

Pengunaan video learning dalam mata kuliah IImu Lingkungan sebagai pemicu untuk aktivitas diskusi. Penelitian Maimunah et al. (2020) memberikan hasil bahwa video efektif digunakan untuk membangun kegiatan diskusi antara mahasiswa maupun antara dosen dengan mahasiswa. Penggunaan video dalam pembelajaran juga akan dapat membantu mahasiswa menyimpulkan materi pembelajaran yang sudah diterima. Melalui penggunaan video learning materi pencemaran lingkungan membantu terciptanya proses pembelajaran yang berpusat pada mahasiswa (student centered) bukan sebaliknya (teacher centered). Studi Delen et al. (2014) mengungkapkan bahwa penggunaan video berbasis lingkungan dapat mendukung pengaturan diri dan proses belajar peserta didik secara mandiri (student centered). Ketika pembelajaran dirancang dan dikembangkan menggunakan video berbasis lingkungan dapat membuat lingkungan menjadi lebih interaktif. Penelitian Hamalosmanoglu et al. (2020) menunjukkan bahwa video efektif digunakan dalam proses pembelajaran pendidikan lingkungan. Penggunaan video dengan konten materi lingkungan dapat berdampak kepada calon guru dalam aspek perilaku terhadap isu-isu lingkungan, sikap terhadap persoalan limbah padat dan daur ulang serta kepedulian terhadap lingkungan (Hamalosmanoglu et al., 2020; Koyunlu Ünlü, 2020). Menurut Suwandi et al. (2017) penggunaan video dalam proses pembelajaran dapat menumbuhkan motivasi, minat dan 
antusiasme mengikuti pembelajaran. Tampilan audio visual dapat meningkatan antusiasme belajar, sehingga peserta didik menjadi tekun dan serius untuk memahami materi dari tayangan video sehingga daya serap terhadap materi yang diberikan cukup tinggi. Peserta didik lebih tertarik dengan konten materi yang disajikan dalam bentuk audio-visual sehingga dapat meningkatkan semangat belajar. Kondisi tersebut dapat membuat suasana kelas menjadi kondusif sehingga tingkat pemahaman terhadap materi akan semakin meningkat. Hal tersebut diperkuat dengan hasil penelitian Zaneldin et al. (2019) bahwa mahasiswa berharap memiliki video pembelajaran yang dikembangkan oleh pengajar dan diposting di website prodi, dan konten video sejalan dengan visi institusi. Pendekatan tersebut untuk membuat fasilitas lingkungan kelas menjadi lebih baik, materi perkuliaha tersedia untuk mahasiswa kapan saja dan dimana saja di platform e-learning (Ahmed \& Zaneldin, 2013). Sementara penelitian Miarsyah et al. (2019) menyebutkan bahwa di sisi lain penggunaan multimedia pembelajaran dapat meningkatkan tanggung jawab serta kepedulian terhadap lingkungan.

Media pembelajaran berbentuk video memiliki kelemahan dan kelebihan. Menurut (Sanaky, 2011) kelebihan video yaitu dapat menampilkan materi dan objek belajar secara konkret, dapat menyampaikan pesan secara nyata sehingga dapat menambah pengalaman belajar mahasiswa dan meningkatkan minat mahasiswa karena media yang digunakan tidak konvensional sehingga akan terhidar dari kejenuhan dalam belajar, media video akan meningkatkan pemahaman dan ingatan serta mudah diakses kapanpun dan dimanapun saja. Hal tersebut didukung dengan profil gaya belajar mahasiswa yang lebih banyak mencari referensi dari internet meggunakan gadget masing-masing. Sedangkan kelemahan media video yaitu tergantung dengan pasokan sumber daya listrik, perangkat gadget/laptop, internet (jika video diupload ke youtube/elearning, komunikasi searah (penggunaan e-learning agar komunikasi dapat berjalan dua arah), dan membutuhkan biaya yang tidak sedikit untuk membuat video pembelajaran. Menurut (Nadhianty \& Purnomo, 2020) salah satu kelemahan video pembelajaran yaitu membutuhkan kouta internet yang mencukupi untuk mengaksesnya. Kelemahan tersebut dapat diatasi dengan mengunduh dahulu video pembelajaran yang akan dilihat.

\section{SIMPULAN}

Gain score untuk kelas $A, B$, dan $C$ diperoleh kategori sedang $(0,3 \leq g \geq 0,7)$, menunjukkan terdapat peningkatan hasil belajar dengan menggunakan video learning materi Pencemaran Lingkungan. Hasil uji t menunjukkan terdapat perbedaan signifikan antara nilai prates dan postes sehingga video learning efektif digunakan dalam proses pembelajaran IImu Lingkungan dengan menggunakan e-learning. Penggunaan. Penggunaan video materi pencemaran lingkungan dalam mata kuliah IImu Lingkungan dapat membuat mahasiswa lebih mudah memahami konsep-konsep dasar, melihat permasalahan lingkungan secara nyata dan kontekstual. Video materi pencemaran lingkungan dapat menghadirkan langsung visualisasi pencemaran udara, tanah dan air kepada mahasiswa.

\section{UCAPAN TERIMA KASIH}

Ungkapan rasa terima kasih kami sampaikan kepada Direktorat Riset dan Pengabdian Masyarakat Direktorat Jenderal Penguatan Riset dan Pengembangan, Kementrian Riset Teknologi dan Pendidikan Tinggi yang telah membiayai penelitian ini; kepada Tim peneliti dan tim pendukung yang telah membantu pelaksanaan penelitian serta kepada mahasiwa Prodi Pendidikan Biologi FKIP UAD angkatan 2016. 


\section{RUJUKAN}

Ahmed, W. K., \& Zaneldin, E. (2013). E-learning as a stimulation methodology to undergraduate engineering students. International Journal of Emerging Technologies in Learning, 8(3), 4-7. https://doi.org/10.3991/ijet.v8i3.2550

Battezzati, L., Coulon, A., Graf, D., Mansouri, I., Ryan, M., \& Walker, R. (2004). E-learning for teacher and trainers. European Centre of the Development of Vocational Training.

Caterhall, P. (2005). Delivering E-Learning for Information Services in Higher Education. In New Library World (Vol. 106, Issue 9/10). Chandos Publishing. https://doi.org/10.1108/03074800510623164

Creswell, J. W. (2014). Research Design: Qualitative, Quantitative, and Mixed Methods Approaches (4th ed.). Sage Publication India Pvt. Ltd.

Daryanto. (2010). Media Pembelajaran. Gava Media.

Delen, E., Liew, J., \& Willson, V. (2014). Effects of interactivity and instructional scaffolding on learning: Self-regulation in online video-based environments. Computers and Education, 78, 312-320. https://doi.org/10.1016/j.compedu.2014.06.018

El-Ariss, B., Zaneldin, E., \& Ahmed, W. (2021). Using videos in blended e-learning for a structural steel design course. Education Sciences, 11(6). https://doi.org/10.3390/educsci11060290

Hamalosmanoglu, M., Kizilay, E., \& Saylan Kirmizigül, A. (2020). The Effects of Using Animated Films in the Environmental Education Course on Prospective Teachers' Behavior towards Environmental Problems and Their Attitude towards Solid Waste and Recycling. International Online Journal of Education and Teaching, 7(3), 1178-1187.

Hanafi, Y., \& Ma'rifah, D. R. (2018). Pengembangan Media Pembelajaran E-Learning Pada Mata Kuliah IImu Lingkungan di Program Studi Pendidikan Biologi FKIP UAD. November, 51-57. https://proceeding.unnes.ac.id/index.php/SNMIPA/article/view/210

Hill, J. L., \& Nelson, A. (2011). New technology, new pedagogy? Employing video podcasts in learning and teaching about exotic ecosystems. Environmental Education Research, 17(3), 393-408. https://doi.org/10.1080/13504622.2010.545873

Ivers, K. S., \& Barron, A. E. (2002). Multimedia Projects in Education: Designing, Producing, and Assessing (2nd ed.). teacher ideas press.

Koyunlu Ünlü, Z. (2020). Analysis of short films of prospective teachers on environmental awareness. International Electronic Journal of Environmental Education, 10(2), 136-146.

Ma'rifah, D. R., Hanafi, Y., Alif, G., \& Rizki, F. (2019). Profil Gaya Belajar Mahasiswa Pada Mata Kuliah IImu Lingkungan Berbasis Blended Learning Profile of Student Learning Styles In Environmental Science. 3, 37-42. https://jurnal.um-palembang.ac.id/dikbio/article/view/1198

Maimunah, Nurzaelani, M. M., Septiani, M., \& Suartika, I. (2020). Uji Efektivitas Media Video untuk Pembelajaran Blended Learning di Universitas Ibn Khaldun Bogor. Prosiding: Hasil Penelitian Dosen Universitas Ibn Khaldun Bogor, 4, 223-228.

Miarsyah, M., Sigit, D. V., Ichsan, I. Z., Fadrikal, R., \& Suprapto, M. (2019). Lekersmulia: Improving indonesian students' environmental responsibility using multimedia in environmental learning. International Journal of Scientific and Technology Research, 8(12), 1639-1643.

Munir. (2013). Multimedia Konsep dan Aplikasi dalam Pendidikan. Alfabeta.

Nadhianty, A., \& Purnomo, A. (2020). Implementation Podcast and Learning Video To Connecting in Distance Learning on Higher Education. Proceeding International Conference on Islamic Education, 5(4), 24-29.

Ningtiyas, Y. T. A., \& Anistyasari, Y. (2020). Studi Literatur : Pengaruh Penggunaan Video Sebagai Media Pembelajaran Di Perguruan Tinggi. Jurnal IT-EDU, 05(01), 417-424.

Patterson, N., Schultz, M., Wood-Bradley, G., Lanham, E., \& Adachi, C. (2020). Going digital to enhance the learning of undergraduate students. Journal of University Teaching and Learning Practice, 17(3), $1-15$.

Prastowo, A. (2014). Panduan Kreatif Membuat Bahan Ajar Inovatif (D. Wijaya (ed.); 1st ed.). Diva Press. Rizki, G. A. F., \& Daniamiseno, A. G. (2019). Pengembangan Model Blended Learning Dengan 
Pendekatan Cooperative Mata Kuliah IImu Lingkungan. 6(1), 42-54.

Sanaky, H. (2011). Media Pembelajaran: Buku Pegangan Wajib Guru Dan Dosen. Kaukaba.

Smaldino, S. E., Lowther, D. L., \& Mims, C. (2010). Instructional technology and media for learning. In K. Davis (Ed.), Pearson (12th ed.). Pearson.

Suwandi, Dimyati, E., \& Yuniar. (2017). Efektivitas Penggunaan Media Video Pembelajaran Dalam Meningkatkan Keterampilan Menulis Dan Kemampuan Memahami Konsep Makna Denotasi Dan Konotasi. 2(3).

Uno, H. B., \& Lamatenggo, N. (2014). Teknologi Komunikasi dan Informas Pembelajaran. Bumi Aksara. Zaneldin, E., Ahmed, W., \& El-Ariss, B. (2019). Video-based e-learning for an undergraduate engineering course. E-Learning and Digital Media, 16(6), 475-496. https://doi.org/10.1177/2042753019870938

Zhang, D., Zhou, L., Briggs, R. O., \& Nunamaker, J. F. (2006). Instructional video in e-learning: Assessing the impact of interactive video on learning effectiveness. Information and Management, 43(1), 1527. https://doi.org/10.1016/j.im.2005.01.004 